\title{
Magnetic Susceptibility Data for Some Exposed Bedrock in the Western Conterminous United States
}

Data Series 804 



\section{Magnetic Susceptibility Data for Some Exposed Bedrock in the Western Conterminous United States}

By Mark E. Gettings and Mark W. Bultman

Data Series 804 


\title{
U.S. Department of the Interior SALLY JEWELL, Secretary
}

\section{U.S. Geological Survey Suzette M. Kimball, Acting Director}

\author{
U.S. Geological Survey, Reston, Virginia: 2014
}

For more information on the USGS - the Federal source for science about the Earth, its natural and living resources, natural hazards, and the environment - visit http://www.usgs.govor call 1-888-ASK-USGS

For an overview of USGS information products, including maps, imagery, and publications, visit http://www.usgs.gov/pubprod

To order this and other USGS information products, visit http://store.usgs.gov

Any use of trade, product, or firm names is for descriptive purposes only and does not imply endorsement by the U.S. Government.

Although this report is in the public domain, permission must be secured from the individual copyright owners to reproduce any copyrighted material contained within this report.

Suggested citation:

Gettings, M.E., and Bultman, M.W., 2014, Magnetic susceptibility data for some exposed bedrock in the western conterminous United States: U.S. Geological Survey Data Series 804, 5 p., with graphical user interface, http://dx.doi. org/10.3133/ds804. 


\section{Contents}

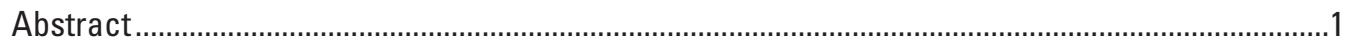

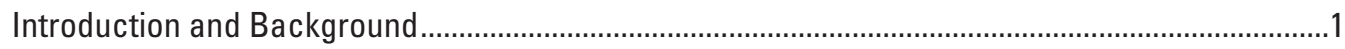

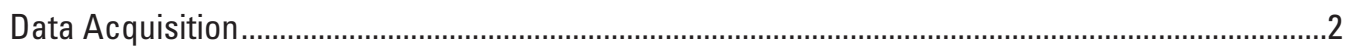

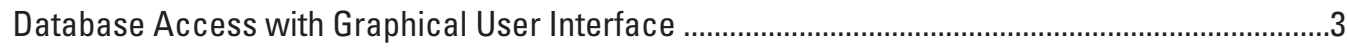

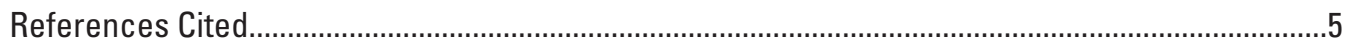

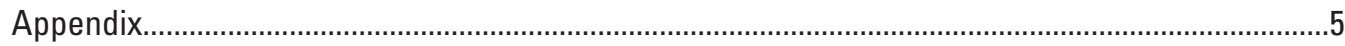

\section{Figures}

1. The Mozilla Firefox ${ }^{\mathrm{TM}}$-based graphical user interface of magnetic susceptibility data for some bedrock in the Western United States. . . .4

\section{Tables}

1. File format of database of magnetic susceptibilities for some bedrock in the Western United

States. 


\section{Conversion Factors}

SI to Inch/Pound

\begin{tabular}{lll}
\hline \multicolumn{1}{c}{ Multiply } & \multicolumn{1}{c}{ By } & \multicolumn{1}{c}{ To obtain } \\
\hline centimeter $(\mathrm{cm})$ & Length & \\
millimeter $(\mathrm{mm})$ & 0.3937 & inch (in) \\
meter $(\mathrm{m})$ & 0.03937 & inch (in) \\
meter $(\mathrm{m})$ & 3.281 & foot (ft) \\
\hline & 1.094 & yard (yd) \\
\hline cubic centimeter $\left(\mathrm{cm}^{3}\right)$ & Volume & cubic inch $\left(\mathrm{in}^{3}\right)$ \\
\hline & 0.06102 & \\
\hline grams per cubic centimeter $\left(\mathrm{gm} / \mathrm{cm}^{3}\right)$ & Density & pounds per cubic inch $\left(\mathrm{lb} / \mathrm{in}^{3}\right)$ \\
\hline
\end{tabular}




\title{
Magnetic Susceptibility Data for Some Exposed Bedrock in the Western Conterminous United States
}

\author{
By Mark E. Gettings and Mark W. Bultman
}

\begin{abstract}
In-place rock magnetic susceptibility measurements for 746 sites in the western conterminous United States are reported in a database. Of these 746 sites, 408 sites are in the Silverton Caldera area of the San Juan Mountains of southwestern Colorado. Of the 408 sites in the Silverton Caldera area, 106 sites are underground. The remaining 338 sites outside the Silverton Caldera area were on outcropping rock, are distributed from southern Arizona to northwestern Wyoming, and include data from California, Nevada, Utah, Colorado, and New Mexico. Rock-density measurements are included for some sites. These data have been collected by various U.S. Geological Survey studies from 1991 through 2012 and are intended to help improve geophysical modeling of the Earth's crust in the Western United States. A map-based graphical user interface is included to facilitate use of the data.
\end{abstract}

\section{Introduction and Background}

Total field magnetometers used in magnetic surveys of the Earth measure the vector sum of the following: (1) the magnetic field generated internally by the Earth and approximated by the International Geomagnetic Reference Field (IGRF), (2) the diurnal or transient magnetic field generated by interaction of the internal magnetic field with solar wind, (3) the induced magnetic field generated by the interaction of the Earth's internal magnetic field and the magnetic susceptibility of rock masses near the magnetometer, and (4) the remanent magnetic field component of rock masses near the magnetometer (Morris and others, 2007). Induced magnetization is the component of magnetism in a material produced in response to an external applied magnetic field; it ceases to exist when the applied field is removed. Remanent magnetization is the permanent magnetization that remains in a material when the applied external field is removed, and it is essentially unaffected by weak magnetic fields (Clark, 1997). The induced and remnant fields give rise to magnetic anomalies of interest for geologic interpretation. These anomalies are created by contrasts in magnetic susceptibility and remanence at contacts between adjacent rock masses of differing physical properties. The IGRF is known (Working Group V-MOD, 2010) and is usually removed from the acquired data. Additionally, a stationary magnetometer next to the survey area is used to record the same transient magnetic field data as the magnetometer used to acquire the survey data. This allows the transient magnetic field to be removed from the survey data, ensuring magnetic anomalies in the survey data are geologic in origin.

The magnetization of a rock mass, J (magnetic dipole moment per unit volume), is equal to the vector sum of the induced field, $\mathrm{J}_{\mathrm{i}}$, and the remnant field, $\mathrm{J}_{\mathrm{r}}$, that is, $\mathrm{J}_{\mathrm{N}} \mathrm{J}_{\mathrm{i}}+\mathrm{J}_{\mathrm{r}}$. For sufficiently weak fields, such as the Earth's magnetic field, $\mathrm{J}_{\mathrm{i}}$ is approximately proportional to and parallel to the applied field with the constant of proportionality known as the magnetic susceptibility, $k$ (Clark, 1997). Therefore, the magnetization component owing to the rock mass' susceptibility is equal to $\mathrm{J}_{\mathrm{i}}=k \mathrm{~F}$, where $\mathrm{F}$ is the magnitude of the Earth's internal field in amperes per meter, which can be approximated by the IGRF.

$\mathrm{J}_{\mathrm{r}}$ is a quasi-permanent magnetization inherent in the rock mass and composed of primary and possibly secondary magnetizations. The primary remanent magnetization for igneous rocks is thermoremanent magnetization, acquired by cooling and solidification of an igneous rock from above the Curie temperature. For sedimentary rocks, the primary remanent magnetization is detrital remanence, the result of the alignment of magnetic sediments with the Earth's magnetic field before being incorporated into a sedimentary rock. Secondary remanent magnetization includes chemical remanent magnetization, which records the magnetization of the Earth's magnetic field from low-temperature crystallization of minerals, viscous remanent magnetization from ferromagnetic minerals exposed for a long time to a magnetic field with a stable orientation, and several generally less important components.

The Koenigsberger ratio, Q, is the ratio of the remanent magnetization to the induced magnetization for a rock mass, $\mathrm{J}_{\mathrm{r}} / \mathrm{J}_{\mathrm{i}}$. The total magnetization of a rock mass is the vector sum of $\mathrm{J}_{\mathrm{r}}$ and $\mathrm{J}_{\mathrm{i}}$. The direction of $\mathrm{J}_{\mathrm{i}}$ is always approximated by the direction of the Earth's present-day magnetic field. The direction of $\mathrm{J}_{\mathrm{r}}$ is dependent on the direction of the Earth's magnetic field at the time the remanence was incorporated into the rock and on any tectonic movement in that the rock mass since recording the past Earth's magnetic field. If the rock mass is aligned near the present-day magnetic field, the magnetization of the rock mass will increase. If the alignment of the rock mass differs from the present-day alignment by 180 degrees, as it might from a recent magnetic reversal, it will lower the observed magnetization of the rock mass or create a dominant reversed magnetization if $Q>1$. If $J_{r}$ points 90 degrees from $\mathrm{J}_{\mathrm{i}}$, $\mathrm{J}_{\mathrm{r}}$ will not contribute to the magnetization of the rock mass. 
The remanence vector cannot have any possible orientation; rather, the orientation must be compatible with the expected age of remanence acquisition (Morris and others, 2007) and with tectonic activity since that time.

If both the susceptibility and remanence vector of a rock mass are known, then the complete anomaly owing to a rock mass can be defined. However, neither susceptibilities nor remanences generally are known. Susceptibility often is estimated by lithology and remanence often is ignored because of the difficulty in acquiring the remanent magnetization. The database presented in this report is intended to aid in modeling the Earth's crust by supplying magnetic susceptibility measurements for some bedrock in the western conterminous United States.

\section{Data Acquisition}

This database presents magnetic susceptibilities for some bedrock in the Western United States acquired by the authors and others between 1991 and 2012. The work was associated with various U.S. Geological Survey (USGS) projects and has reached a volume significant enough to be published. Three separate instruments were used to measure magnetic susceptibility. From 1991 to 2001, a Sapphire Instruments model SI-1 was used. From 2002 to 2010, a ZH Instruments SM-30 was used, and from 2011 through 2012, a Terraplus KT-10 was used.

The Sapphire Instruments model SI-1 is equipped with a $20 \times 20$-centimeter $(\mathrm{cm})$ flat field coil, and is designed for measurements on outcrops. In the laboratory, many tests and repeated measurements have shown that the SI-1 has a precision of $2.5 \times 10^{-6}$ (in the International System of Units, SI) or greater, providing the sample volume is adequate. In the field, however, results have been more ambiguous, and experience indicates that the precision as indicated by the standard deviation of repeated measurements is often about 0.4 percent of the mean magnetic susceptibility (Gettings and others, 1994). For example, an outcrop that served as a calibration site at the Idarado Mine Offices about 10 meters (m) from the nearest building had a mean magnetic susceptibility of $1.272 \times 10^{-2}$ (SI) and a standard deviation of $6.836 \times 10^{-4}(\mathrm{SI})$ for 22 sets of five measurements each during a 17-day period. In an area well removed from power lines, three occupations of five measurements each during a 5-hour period had a mean magnetic susceptibility of $1.772 \times 10^{-5}(\mathrm{SI})$ with a relatively large standard deviation of $5.57 \times 10^{-7}$ (SI) (Gettings and others, 1994). Power fluctuations in power lines and other magnetic disturbances cause variations of the background that contribute to a less precise measurement of outside conditions. Absolute accuracy has not been evaluated, but the manufacturer claims a greater than 80-percent accuracy of model SI-1 under all conditions (Gettings and others, 1994). The inductive technique used by the SI-1 to measure magnetic susceptibility does not work in conductive substances and yields negative values because of eddy currents.
The default sample time of 2.6 seconds for each measurement was used at all sites measured with the SI-1. The field coil for the SI-1 measures the average susceptibility for a $20 \times 20-\mathrm{cm}$ area to a depth of about $15 \mathrm{~cm}$, and, therefore, samples a volume of about 6,000 cubic centimeters $\left(\mathrm{cm}^{3}\right)$. Most outcrops measured were about $2 \times 3 \mathrm{~m}$ in size with five sample spots randomly distributed across the outcrop. For consistency in measurements, only relatively flat portions of the outcrop where the sample coil made close contact were measured; measurements on rough surfaces always yielded larger standard deviations because of gaps beneath the coil (Gettings and others, 1994).

Data acquired from 2002 to 2010 were measured with a ZH Instruments SM-30 magnetic susceptibility meter. This instrument has a sensitivity of $1 \times 10^{-7}(\mathrm{SI})$, an $8 \mathrm{kHz}$ oscillator, and a 50-millimeter ( $\mathrm{mm}$ ) coil. The sensor is designed to acquire 90 percent of its signal from the first $20 \mathrm{~mm}$ of the rock, which allows more accurate readings on uneven surfaces of all rock types (ZH Instruments, 2008). Outcrop susceptibility was estimated by making 5 to 20 or more readings at random locations with minimum spacing of approximately 20 $\mathrm{cm}$ on the outcrop face. Measurements taken at outcrops with large numbers of readings (greater than 20) may be spaced more closely.

Data acquired in 2011 and 2012 were measured with a Terraplus KT-10 susceptibility meter. This instrument has a sensitivity of $1 \times 10^{-6}(\mathrm{SI})$, a $10 \mathrm{kHz}$ oscillator, and a $65-\mathrm{mm}$ coil with a 45-degree angle (Terraplus, 2012). Measurements were taken at 20 times per second, averaged over five consecutive readings, and stored so that four readings per second were recorded. For most outcrops, 120-180 measurements were recorded (30-45 seconds of data acquisition time). The instrument was moved continuously along a level part of an outcrop during this time period.

In some instances, particularly with measurements taken with the KT-10, rapid transient geomagnetic fluctuations caused the measurement to drift significantly during acquisition. In most cases, the drift is nearly linear for the measurement duration. In these cases, a least- squares trend line was fit to the raw data and subtracted to yield a de-trended dataset from which estimates of mean and quartiles were taken. In these cases, the original data file is included in addition to the de-trended one.

When possible, hand samples of the outcrop were collected. Hand samples were hammered from the outcrop and were selected as representative of the outcrop. The samples generally range in size from 10 to $20 \mathrm{~cm}$. These samples were used to better determine outcrop lithology and to make dry-bulk density measurements for about 30 samples from the Patagonia Mountains, Arizona, based on the buoyancy method. These data were included in the database.

The database is provided in three formats. Two of those formats are "MagSus.xlxs," which is in Microsoft Excel ${ }^{\circledR}$ format, and "MagSusData.csv," which is a text (ascii) file in comma-separated value format. The structure of the database in these two formats is given in table 1. The third format 
incorporates the use of a graphical user interface (GUI) to access the data. This map-based third format includes access to a large amount of additional information including images of the sample location in some cases and is described in the next section. Access to all three formats is available online only at http://pubs.usgs.gov/ds/804/.

\section{Database Access with Graphical User Interface}

The GUI was built for the database in Javascript ${ }^{\circledR}$ and Google Maps ${ }^{\mathrm{Tm}}$ API. This GUI was written for the Mozilla Firefox $^{\text {TM }}$ Web browser, an open-source, public-domain web browser that can be downloaded from http://www.mozilla. org/en-US/. The GUI also works with Microsoft Internet Explorer $^{\circledR}$ and Google Chrome ${ }^{\mathrm{TM}}$, but requires special instructions with these browsers in order to read local files. Please see the "readme.txt" for an explanation of how to use the database with Microsoft ${ }^{\circ}$ Internet Explorer and Google Chrome ${ }^{\mathrm{TM}}$. The user must have access to the Internet to use this GUI because it uses Google Maps $^{\text {TM }}$ to display the data locations geographically. To access the GUI, open the file "MagSus.htm" with Mozilla Firefox ${ }^{\mathrm{TM}}$.

Once opened, the GUI displays a map of the Western United States with many red, blue, and green triangles, each representing a location where magnetic susceptibility has been acquired (fig. 1). Red triangles are for surface data with one measurement at a given location, blue triangles are underground sites (collected in mine adits and tunnels), and green triangles are sites that have multiple measurements at one location. An information window is displayed to the left of the map with a key and other information. The map can be panned by clicking and depressing the left mouse button, while moving the cursor. Controls in the upper left-hand corner of the map allow the user to zoom into a desired location. Controls in the upper right-hand corner allow the user to display a road map (default), a satellite-data-based map, or a hybrid map showing both (fig. 1).

When the user clicks any triangle, a window displays in the map showing data associated with that site. Additionally, if available, an image of the outcrop displays to the right of the data window. The images may be large, and the user may need to pan the map to see the entire image. The data window also has a link that connects the user to a data file for the site. At older sites, where data was acquired before 2000, the data file may simply include a summary of the data acquired at that site. At more recent sites, the data file will include all individual magnetic susceptibility readings taken at the outcrop that are summarized in the data window. A description of data files is given in appendix 1 . The data window also has a link to the directory that contains the data file or files and image file or files for the site. The image files provide access to the original high-resolution image at any site that has an image; the directory also may include multiple images from that site.
Table 1. File format of database of magnetic susceptibilities for some bedrock in the Western United States.

\begin{tabular}{|c|c|}
\hline Column & Contents \\
\hline 1 & Site latitude in decimal degrees \\
\hline 2 & Site longitude in decimal degrees \\
\hline 3 & Site name \\
\hline 4 & Datum \\
\hline 5 & $\begin{array}{l}\text { Rock sample dry-bulk density (if available, grams per } \\
\text { cubic centimeter) }\end{array}$ \\
\hline 6 & Outcrop mean susceptibility (SI) \\
\hline 7 & $\begin{array}{l}\text { Susceptibility at first quartile for sites with more than } \\
20 \text { readings }\end{array}$ \\
\hline 8 & $\begin{array}{l}\text { Susceptibility at second quartile for sites with more } \\
\text { than } 20 \text { readings }\end{array}$ \\
\hline 9 & $\begin{array}{l}\text { Susceptibility at third quartile for sites with more than } \\
20 \text { readings }\end{array}$ \\
\hline 10 & Number of susceptibility readings at site \\
\hline 11 & Instrument used for susceptibility measurements \\
\hline 12 & $\begin{array}{l}\text { FSF = Frederick S. Fisher, U.S. Geological Survey } \\
\text { (USGS), retired, Montrose, Colorado } \\
\text { JM = Jim Mayer, Tucson, Arizona } \\
\text { Keith Howard = Keith Howard, USGS. Menlo park, } \\
\text { California } \\
\text { Mark Bultman = Mark Bultman, USGS, Tucson, } \\
\text { Arizona } \\
\text { MEG = Mark E. Gettings, USGS, Tucson, Arizona } \\
\text { PEG = Paul E. Gettings, University of Utah, Salt } \\
\text { Lake City, Utah }\end{array}$ \\
\hline 13 & Date \\
\hline 14 & Time (Greenwich Mean Time) \\
\hline 15 & Elevation \\
\hline 16 & $\begin{array}{l}\text { Geologic information at site } \\
\text { Abbreviations used: bxd, brecciated; altn, altera- } \\
\text { tion; sulph, sulphides; pyr, pyrite; frax, fractures; } \\
\text { DOMN, degrees off magnetic north; MN, MS, } \\
\text { ME, MW, magnetic north, south, east, and west, } \\
\text { respectively; P, Remanent magnetic polarity from } \\
\text { oriented hand sample: U, not determined; X, mea- } \\
\text { sured but no pole determined; N, normally polar- } \\
\text { ized (that is, approximately in direction of present } \\
\text { Earth magnetic field); R, reversely polarized }\end{array}$ \\
\hline 17 & URL link to site data file \\
\hline 18 & URL link to image of site if available \\
\hline
\end{tabular}

Green triangles may be sites where one rock type directly overlays another rock type vertically, or they may be sites that have multiple measurements on one lithology at different times. When the user clicks a green triangle, the information window displays with an additional link to the data file for the duplicate site (or sites) at that location. The geologic descriptions in the data files for duplicates identify the duplicate sites and explain why the location has multiple sites.

In the Ruby Mountains region of Nevada, 47 data sites were collected by Keith Howard (USGS). These data are 
included in the database, and Keith Howard's original data can be accessed from the GUI in Microsoft Excel ${ }^{\circledR}$ format and from the file "MagSus files/data/nv/RubyMtns/Nevada.xls." Within this data, site locations are listed in column B. For each site, there are one-to-several different samples with different lithology taken near that site.

In southern Arizona, linework for a geologic map covering the Patagonia Mountains has been added and can be accessed in the GUI (Simons, 1974). This linework can be displayed by clicking the "Simons' linework" radio button in the information window to the left of the map (fig. 1). Clicking the radio button automatically zooms the map to southern Arizona and displays all relevant magnetic susceptibility site location triangles. To remove this geologic linework, click the "no geologic linework shown" radio button (fig. 1). A link to an image of Simons' geologic map of the Patagonia Mountains region is at the bottom of the left-hand information window (fig. 1). Clicking this link displays an image of the map in a new window or tab. This image can be used to correlate the geologic linework displayed in the GUI with actual mapped geologic units displayed on the map.

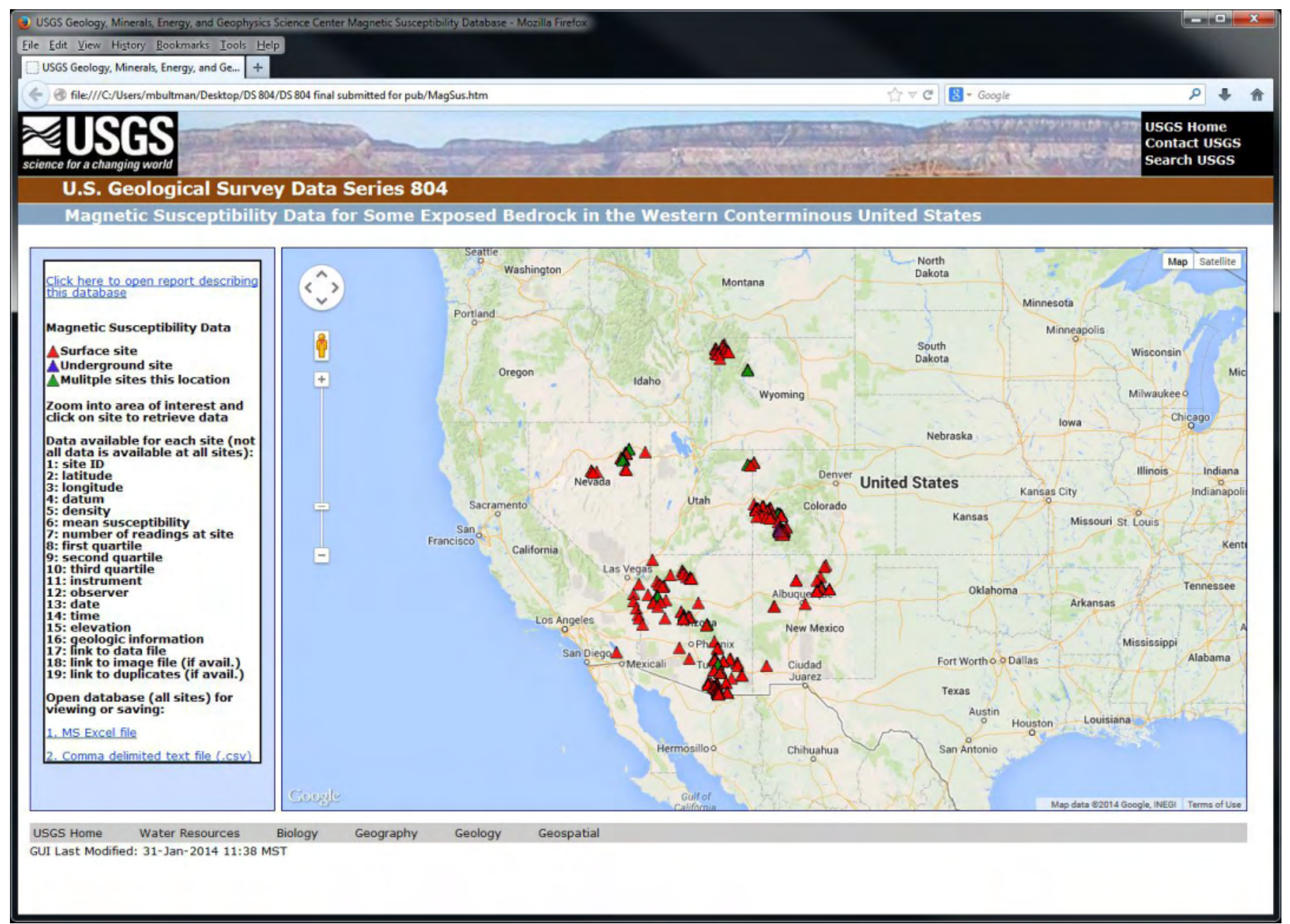

Figure 1. The Mozilla Firefox ${ }^{\mathrm{TM}}$-based graphical user interface of magnetic susceptibility data for some bedrock in the Western United States. 


\section{References Cited}

Clark, D.A., 1997, Magnetic petrophysics and magnetic petrology-Aids to geological interpretation of magnetic surveys: Australian Geological Survey Organisation (AGSO) Journal of Australian Geology and Geophysics, v. 17, p. 83-103.

Gettings, M.E., Fisher, F.S., Gettings, P.E., and Luedke, R.G., 1994, Some magnetic properties of rocks from the Silverton Caldera area, western San Juan Mountains, Colorado: U.S. Geological Survey Open-File Report 94-291, 38 p.

Morris, B., Ugalde, H., and Thomson, V., 2007, Magnetic remanence constraints on magnetic inversion models: The Leading Edge, Society of Exploration Geophysicists, August 2007, p. 960-964.

Simons, F.S., 1974,Geologic map and sections of the Nogales and Lochiel Quadrangles, Santa Cruz County, Arizona: U.S. Geological Survey Miscellaneous Investigations Series Map I-762, scale 1:48,000.

Working Group V-MOD, 2010, International Geomagnetic Reference Field-The eleventh generation: International Association of Geomagnetism and Aeronomy Working Group V-MOD, Geophysical Journal International, v. 183, issue 3, p. 1216-1230, doi:10.1111/ j.1365-246X.2010.04804.x, accessed July 16, 2013, at http://onlinelibrary.wiley.com/doi/10.1111/j.1365246X.2010.04804.x/abstract.

Terraplus, 2012, KT-10 magnetic susceptibility meter: Terraplus Web site, accessed July 16, 2013, at http://www. terraplus.ca/products/pdf/kt-10-v11.pdf.

ZH Instruments, 2008, SM-30 shirt pocket-size magnetic susceptibility meter: ZH Instruments Web site, accessed July 16, 2013, at http://www.zhinstruments.com/.

\section{Appendix 1. Format for Data Files}

Data files differ based on who acquired the data. There are three types of data files:

1. Data files acquired by Mark Gettings are text files (.txt) with following format:

\#site_name latitude_degrees latitude_minutes longitude_degrees longitude_minutes elevation \#short description of geology if available \#data_acquired_by instrument units date_(eg 20100311) time_(GMT eg 1943) \#site image file name if available

Then a repeat of the following on each line for as many readings as are in the data:

counter susceptibility_reading_(SI) $\log 10$ [(susceptibility reading *1000)]_(SI)

Example:

\#I25-13536.758 10555.0167274

\#Xpg intrusive $5 \mathrm{~m}$ vert road cut west side 125 \#MEG SM-30 SI 201001241430 \#I25 1.JPG

$\begin{array}{ll}1 & 1.900 e-04-3.721 e+00 \\ 2 & 2.050 e-04-3.688 e+00 \\ 3 & 1.580 e-04-3.801 e+00 \\ 4 & 3.670 e-04-3.435 e+00 \\ 5 & 2.380 e-04-3.623 e+00\end{array}$

2. Data acquired by Mark Bultman are the original digital field notes that are composed of text (.txt) or Adobe (.pdf) files for each site. Each site has a geologic description, a list of all susceptibility readings for that site (in SI $\times 1,000$ units), and images of the site when the data is in Adobe (.pdf) format.

3. Data acquired by Keith Howard are the original data that Keith Howard gave to the authors. The data are composed of a Microsoft Excel file that lists sites in column B and that has different lithologies in row.

4. For each site, the susceptibility reading is listed for the lithology if it is present at the site. The susceptibility is given in SI $\times 1,000$ units. 
Page left intentionally blank 
Menlo Park Publishing Service Center, California

Manuscript approval date November 5, 2013

Edited by John Osias and James W. Hendley II

Design and layout by Vivian Nguyen 
